\title{
Per una Pedagogia de la interioritat
}

\author{
Eric Ortega González (Universitat de Barcelona)
}

\author{
Maria Rosa Buxarrais i Marta Burguet, M. (Coords.). Aprender a \\ ser. Por una pedagogía de la interioridad. Barcelona, \\ Editorial Graó, 2016, 184 pàg.
}

Sembla evident que en els últims temps les qüestions relacionades amb l'educació del caràcter, la reivindicació del voluntariat com escola d'educació cívica i les propostes pedagògiques sorgides del que s'ha denominat «educació emocional» han dominat, de manera visible, tots els discursos sobre educació en valors i/o per a la ciutadania. No ha ocorregut el mateix, no obstant, amb aquells aspectes -també morals- que Delors (1996) va acollir sota l'epígraf que donava nom a un dels reptes educatius per al segle XXI -l'aprendre a ser- si prenem aquest «ser» en sentit fort, és a dir, en el sentit del cultiu de la nostra pròpia interioritat.

En efecte, el llibre que coordinen les professores Buxarrais i Burguet ocupa un espai, el de la pedagogia de la interioritat, que malgrat formar part de la cultura de l'ésser que travessa tota la tradició pedagògica occidental (les referències al pronaos del temple de Delfos es donen en més d'un capítol) sembla que, en els últims temps, s'ha vist desplaçada per una cultura del tenir (p. 43). Les causes, per suposat nombrosíssimes, no només apunten, com bé senyalen alguns dels autors del llibre, al canvi que el gir economicista ha generat sobre les polítiques educatives (p. 55) sinó també a un ritme marcat per la immediatesa que el progrés tecnològic acompanyat de la competitivitat i el consum -com a trets essencials de les nostres societats-imposen arreu.
Així, en aquest convit que ens porta del «pantacentrisme» (p. 102), o el que és el mateix, de l'exaltació de la pantalla com a instància mediadora i com a objecte hegemònic de la nostra atenció, a la interioritat com a finalitat última de la tasca educativa, observem, en cadascun dels treballs, una perspectiva humanista que més enllà de tota temptació instrumental creu que l'educació ha de desenvolupar indefugiblement cadascuna de les dimensions de la personalitat humana.

Les perspectives des de les que s'aborda el treball de la interioritat al llarg dels setze capítols que conformen el llibre procedeixen d'autors de molt diverses disciplines -filòsofs, neurocientífics, pedagogs, mestres, etc.- així com de contextos culturals $i$ experiències pedagògiques ben diferents; des de la ciutat de Santa María a l'Argentina a Barcelona, tot passant per Jaén o la colombiana Cali. Tanmateix, i malgrat aquesta diversitat, es deixen endevinar certes complicitats entre els seus autors no només en la mesura en què per a tots ells l'educació de l'ésser suposa un repte en el que paga la pena aventurar-se sinó també en la consideració que davant d'altres aprenentatges, igualment bàsics $i$ necessaris, el treball pedagògic sobre l'ésser ofereix experiències unitives sobre les que construir la nostra relació tant amb nosaltres mateixos com amb els altres. Tot plegat ens permet allunyar-nos, dit sigui de pas, de qualsevol interpretació que 
jutgi que el desenvolupament de la dimensió interior té com a finalitat última l'ailllament de l'individu.

En vista del que hem dit cal anunciar que l'obra, dividida en dues parts, engloba dos tractaments complementaris a la qüestió del cultiu de la interioritat corresponent, la primera meitat del llibre, a aquells capítols de tendència més teòrica -i en els que, amb tot, s'adverteix la presència dominant de la pràctica- i, la segona meitat, a aquells capítols de caràcter pràctic -fonamentalment, presentació d'experiències de les diverses dimensions sobre les que pot treballar-se la interioritat-, no exemptes, malgrat tot, d'un esforç reflexiu amb vistes a la sistematització teòrica de les mateixes.

En els tres primers capítols ens trobem amb un intent interdisciplinari de fonamentar la pedagogia de la interioritat des de tres òptiques diferents. En primer Iloc, des de la filosofia, on ens trobem, entre altres reflexions d'alt interès, una encertada apel.lació a la bellesa (p. 22) i, per tant, a l'art, en tant que formes de descentrament d'un mateix (amb les clares implicacions morals que això comporta). En segon Iloc, des de la neurociència, a través de la qual se'ns il.luminen els fonaments neurofisiològics que s'amaguen sota els fenòmens associats a la consciencia i l'autoconsciència (emoció, reflexió, atenció, etc.) i se'ns adverteix sobre quins són els condicionants educatius que permeten la fixació de rutes neurals ( $p .38$ ); i en tercer i últim lloc, des de l'ètica de la cura, atès que no hi ha major preocupació per la interioritat que aquella que sorgeix de la cura que ens dispensem tant a nosaltres mateixos fruit, en part, del mateix esforç per autoconèixer-nos - (p. 46) com als altres; conseqüència aquesta del vincle afectiu amb el que estem essencialment travessats.
En els següents capítols, també teòrics, s'abordaran les claus sobre les que poder treballar, en l'escola, la dimensió emocional a través de la promoció d'experiències de fluïdesa i de crear un clima d'aula positiu, càlid i de vincles afectius segurs ( $p$. 61). Així mateix, si convenim que l'escola ha de preocupar-se per el benestar dels seus educands, no podem menys que comprometre'ns amb una escola del ser que integri la consciència de dit benestar en el currículum i que tingui cura dels ritmes dels seus estudiants, es recreï en la diversitat i els hi permeti pensar, dialogar $i$ somiar (p. 91). Posarà punt i final a la primera part del llibre una reflexió sobre les relacions educatives que, fent-se càrrec de la incomoditat pedagògica de la pregunta, advocarà per descriure un camí cap a la interioritat a través de la comprensió, la responsabilitat i la creació com a processos en els que emergeix l'ésser (p. 102).

Els últims capítols, aquells destinats com ja hem advertit- a situar el cultiu del ser sobre realitat concretes, ens ofereixen un ampli ventall d'experiències (totes elles d'alt valor humà) entre les que trobem, només per mencionar alguna, el desenvolupament de la interioritat a través de tallers de treball corporal (p. 126), l'enfocament concret que ha pres el pla de l'OMS Habilidades para la vida en el Colegio Fray Luis Amigó de Cali (p. 142) o el Projecte «GAC A l'escola». Aquesta darrera, promocionada per l'Ajuntament de Mataró, aprofundeix en el desenvolupament del ser a través d'una cultura escolar de mediació i de gestió de conflictes, i posa de relleu que la finalitat última de tot cultiu de la interioritat és «garantizar una real apertura, implicación, compromiso y participación social desde lo más genuino de cada persona» (p. 14).

Ens trobem, doncs, davant d'una obra ambiciosa, de la que podria desenvoluparse, per cada capítol que la constitueix, un 
treball monogràfic, i que a diferència d'altres textos que poden tractar de temàtiques veïnes, llança sobre la pedagogia de la interioritat una mirada rigorosa, ben informada i d'alt poder interpel.lador. En definitiva, una veritable crida a aprendre ( $i$ ensenyar) a ser. 